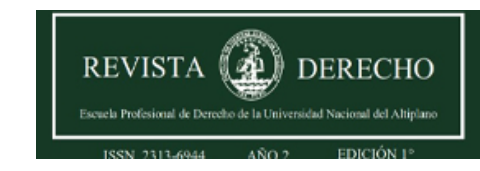

Revista de Derecho

ISSN: 2313-6944

ISSN: 2707-9651

revistaderecho@unap.edu.pe

Universidad Nacional del Altiplano

Perú

\title{
El Pasaje peatonal Lima de Puno (1994-1995) Una crónica de cómo fue su construcción e impacto
}

Reynoso, Christian

El Pasaje peatonal Lima de Puno (1994-1995) Una crónica de cómo fue su construcción e impacto

Revista de Derecho, vol. 6, núm. 2, 2021

Universidad Nacional del Altiplano, Perú

Disponible en: https://www.redalyc.org/articulo.oa?id=671870938001

DOI: https://doi.org/10.47712/rd.2021.v6i2.153

\section{(c) (1)}

Esta obra está bajo una Licencia Creative Commons Atribución 4.0 Internacional. 


\section{El Pasaje peatonal Lima de Puno (1994-1995) Una crónica de cómo fue su construcción e impacto}

\section{The Pedestrian Passage Lima de Puno (1994-1995) A chronicle of its construction and impact}

Christian Reynoso

Pontificia Universidad Católica del Perú, Perú
DOI: https://doi.org/10.47712/rd.2021.v6i2.153

Redalyc: https://www.redalyc.org/articulo.oa? id $=671870938001$

Recepción: 29 Marzo 2021

Aprobación: 30 Julio 2021

Publicación: 05 Agosto 2021

\section{Resumen:}

Las tres cuadras que conforman el actual pasaje peatonal Lima, en el corazón de Puno, han centralizado el paso diario de la vida puneña, como si se tratara de un écran. En dicho pasaje, a diferencia de otras calles y avenidas, sino se han construido, se han acondicionado galerías, tiendas, hoteles, farmacias, restaurantes, agencias de turismo, discotecas, pubs, snacks, oficinas, bancos e instituciones.

Palabras Clave: Pasaje peatonal.

\section{Abstract:}

The three blocks that make up the current Lima pedestrian walkway, in the heart of Puno, have centralized the daily passage of Puno life, as if it were an écran. In this passage, unlike other streets and avenues, galleries, shops, hotels, pharmacies, restaurants, tourist agencies, discos, pubs, snacks, offices, banks and institutions have not been built.

KEYWORDS: Pedestrian passage.

Las tres cuadras que conforman el actual pasaje peatonal Lima, en el corazón de Puno, han centralizado el paso diario de la vida puneña, como si se tratara de un écran. En dicho pasaje, a diferencia de otras calles y avenidas, sino se han construido, se han acondicionado galerías, tiendas, hoteles, farmacias, restaurantes, agencias de turismo, discotecas, pubs, snacks, oficinas, bancos e instituciones.

¿Pero cómo era este jirón antes?

Era como cualquier otro con veredas estrechas, baches y pavimento agrietado. No obstante, nunca dejaba de ser concurrido por ser el nexo entre las dos plazas más importantes de la ciudad: el parque Pino y la plaza de Armas. Hoy como ayer, no ha dejado de ser punto de encuentro. Y si hoy se puede caminar a las anchas, antes había que hacerlo en fila india por las aceras angostas o sobre la pista, por donde vehículos y buses de transporte público pasaban besando las veredas.

A las seis de la tarde se encendían los focos de neón. Era cuando el chato Tahuachaqui abría su ventana de venta de hamburguesas, en la primera cuadra. Y la gente se arremolinaba en torno. Hacia las ocho empezaban a cerrarse las enormes puertas de color rojo de la ferretería Casa Secchi y más allá, las de la farmacia Parodi, aunque nunca las del bar restaurante Las Palmeras, en la segunda cuadra, en el que desde la mañana en el canchón del fondo se jugaba Sapo y se tomaba cerveza hasta el atardecer, hasta el anochecer, mientras se apostaba hasta perderlo todo. Hoy es una galería comercial.

Pero, ¿cómo así el jirón se convirtió en pasaje?

Era 1994, el año de la Modernización Educativa y del Deporte, cuando la Municipalidad Provincial de Puno, bajo la alcaldía de Juan Sotomayor Pérez, decidió modernizar el centro de la ciudad, para lo cual aprobó 
el proyecto de transformación de algunas cuadras centrales del jirón Lima en el "Pasaje Peatonal jirón Lima", obra que sería el regalo a la ciudad en su CCCXXVI aniversario.

La construcción empezó en julio de 1994, estableciéndose a condición de los vecinos y por compromiso de la municipalidad que la obra estaría concluida indefectiblemente en noviembre del mismo año. Así, la municipalidad, los vecinos y los propietarios de predios ubicados en la arteria celebraron un Acta de Conciliación ante el Juzgado de Primera Instancia en respuesta a la acción de amparo que interpusieron los segundos contra la municipalidad y en la que se fijó como fecha límite para la entrega de la obra, el 4 de noviembre de 1994. Había cuatro meses de plazo para la construcción.

A pesar de estas vicisitudes que antecedieron la transformación del jirón Lima, parte de la población estuvo convencida de que el futuro pasaje peatonal sería el símbolo naciente de un nuevo orden para la ciudad, un modernismo altiplánico, forjador de un nuevo modo de vida. Ello implicaría irremediablemente un cambio de rostro, un cambio social del que las generaciones venideras podrían disfrutar.

Sin embargo, la esperanza de ver el cambio de Puno, varado en las postrimerías del milenio, en una ciudad moderna y atrayente, al menos en el cercado de la ciudad, tuvo sus reveses. En principio, la mayoría de vecinos circundantes a las tres cuadras del futuro pasaje se vieron perjudicados por los trabajos de construcción: gigantes montículos de tierra, piedra, arena y cascajo, incesante polvo que concentraba suciedad. A lo que se sumó el ajetreo y los sonidos propios de taladros, tractores y aplanadoras. De esta manera, los vecinos hicieron suyo un gran descontento: tuvieron que cerrar sus establecimientos y negocios, cesó la actividad y la agitación. Ya nadie pasaba por ahí, solo se veían obreros, máquinas, calaminas, bolsas de cemento, cilindros y tierra. Ese era el paisaje que adornaba los días y noches del centro de la ciudad.

Los medios de comunicación, que no supieron ver el lado significativo de este cambio y empuje decisivo para el crecimiento de la ciudad, se ocuparon más bien de tildar a la obra como la sensacional y nueva piscina de la ciudad, producto de las grandes y profundas lagunas que se formaron a consecuencia de las lluvias, días en que la obra se paralizaba o avanzaba con terrible lentitud. Asimismo hicieron suyo el reclamo de los pobladores por haberse cerrado con maderas y calaminas algunas calles perpendiculares al pasaje, dificultando de esta manera el paso y obligando a dar grandes vueltas por las calles adyacentes. Situación que representaba, según dijeron, una falta de respeto a la población por parte de las autoridades ciegas que habían encaminado esta obra como resultado de la improvisación y la prodigalidad administrativa.

Estas críticas se vieron reforzadas cuando pasados los cuatro meses previstos para la ejecución, el tiempo resultó insuficiente. Los trabajos de construcción se habían retrasado y postergado a causa de la desorganización técnica, presupuesto deficiente y falta de prioridad, lo que llevó a que la obra se prolongara por espacio de nueve meses más. Sin más remedio, todos tuvieron que aceptar que tal vez sería una obra de nunca acabar.

Fue así como luego de trece meses, en agosto de 1995, el ya para entonces famoso y retrasado pasaje peatonal estuvo casi listo para inaugurarse y convertirse en el imán que atraería los sueños, deseos y necesidades de los ciudadanos del cercado, quienes, al mismo tiempo, harían de él su ente de existencia y sobrevivencia por tiempo ilimitado, puesto que el pasaje pasó enseguida a valorizarse económicamente y a ser fuente de empleo. El descontento de los vecinos más próximos mudó al presentárseles la oportunidad de reabrir sus negocios, ahora en la lógica de concurridos centros de consumo, o no desaprovecharon la oportunidad de crear rentables empresas y/o alquilar los inmuebles a costos altos.

La pomposa ceremonia de inauguración fue anunciada para el viernes 11 de agosto a las cinco de la tarde con el slogan: "Obra de uso peatonal que jerarquiza el centro de la ciudad y le restituye la naturaleza original del casco urbano céntrico, que se ha ido afirmando en los últimos años por el crecimiento poblacional”. Sin embargo, la felicidad no duró mucho porque a último momento la inauguración fue cancelada y postergada en razón de algunos detalles que impidieron la terminación de la obra. El maestro contratista dijo que el atraso se debía a que en los últimos días sólo habían contado con dos horas de servicio de agua y no pudieron 
terminar con la fase del pulido de las losetas venecianas; asimismo faltó la adecuación y ambientación del desagüe en una calle perpendicular al pasaje.

Una semana después se programó una segunda y esta vez definitiva y oficial inauguración. Así, el sábado 19 de agosto de 1995, al medio día, con bombos y platillos, bailes de Tuntuna, orquesta y abundante cerveza la obra "Pasaje Peatonal jirón Lima" fue inaugurada. En un tabladillo autoridades edilicias, simpatizantes, obreros, vecinos y pobladores, bailaron, libaron y festejaron. Sin embargo, los días posteriores la obra mostró sus primeras deficiencias: habían filtraciones de agua en diferentes zonas debido a que la inclinación del alcantarillado era defectuosa; asimismo, se iniciaron recién los trabajos complementarios para la conexión de cables e instalación de postes de alta tensión para lo cual tuvieron que romper el piso de losetas venecianas y abrir canales en algunos sectores del pasaje y calles aledañas.

Después de la inauguración el sentir popular dejó oír su voz de protesta: cuestionó que la municipalidad destinara un presupuesto elevado para la construcción del pasaje, con la utilización de materiales costosos e innecesarios, además de la tardanza en su ejecución, cuando en la ciudad había otras necesidades y prioridades, puesto que numerosas calles y avenidas requerían atención urgente: ser refaccionadas, parchadas o pavimentadas. Asimismo, un sector de la población dijo sentirse insatisfecha con la gestión municipal. Expresaron que como sus viviendas no se ubicaban en la parte del cercado, entonces eran desatendidos y olvidados por las autoridades, a quienes no les interesaba ocuparse de los barrios periféricos.

Por esos días se supo también de la muerte del famoso Pepe Lezano, conocido y temido hombre de non sancto andar. Igualmente, el 29 de agosto, ocurrió el incendio de la comisaría de Puno, en la plaza de Armas, ocasionado por un corto circuito. El fuego arrasó el segundo piso de la instalación de construcción antigua - que hasta el día de hoy permanece en escombros - y consumió documentos, atestados policiales y los archivos de una parte de la historia republicana de Puno, que allí se guardaban. 